\title{
Fatty acid-mediated inhibition of IL-12 production by murine macrophages is independent of PPAR $\gamma$
}

\author{
Meijuan Zhang and Kevin L. Fritsche* \\ Department of Animal Sciences and the Nutritional Sciences Graduate Program, University of Missouri-Columbia, \\ Columbia, MO 65211, USA
}

(Received 4 August 2003 - Revised 12 December 2002 - Accepted 7 January 2004)

\begin{abstract}
Our laboratory has reported that $n$-3 PUFA can reduce host resistance to Listeria infection, in part, by impairing in vivo IL- 12 biosynthesis. Recently, PUFA were shown to be ligands for PPAR, a novel family of nuclear receptors with three isoforms: PPAR $\alpha$, PPAR $\delta / \beta$ and PPAR $\gamma$. PPAR $\gamma$ is expressed in immune cells, such as T cells and macrophages. Two PPAR $\gamma$ agonists, 15-deoxy- $\Delta^{12,14}$-prostaglandin (PG) $\mathrm{J}_{2}$ and rosiglitazone, have been shown to have immunomodulatory activity in vitro, including inhibiting IL-12 biosynthesis. We hypothesized that $n-3$ PUFA inhibit IL-12 production through activating PPAR $\gamma$. We used thioglycolate-elicited mouse peritoneal macrophages to study the effect of various fatty acids and their oxidized metabolites on in vitro IL-12 production. Our present results demonstrate that both $n-3$ and $n-6$ PUFA can reduce in vitro IL-12 biosynthesis, though less potently than 15-deoxy-PGJ and $_{\text {rosiglitazone. }}$ GW9662, a PPAR $\gamma$ antagonist, reversed the inhibitory effect of rosiglitazone, but not that of PUFA. Our present findings suggest that fatty acid-mediated inhibition of IL-12 production is independent of PPAR $\gamma$.
\end{abstract}

Polyunsaturated fatty acids: Peroxisome proliferator-activated receptor- $\gamma$ : Interleukin 12: Macrophages

Dietary n-3 PUFA are capable of affecting immune responses in both animals and human subjects. Studies have shown that $n-3$ PUFA can diminish cell-mediated immune function, including lymphocyte proliferation, cytotoxicity of natural killer cells, as well as antigen-presentation by macrophages (Calder, 1996, 1998; Harbige, 1998; Wu \& Meydani, 1998). One mechanism by which $n$-3 PUFA modulate immune function is by alteration of cytokine production. Dietary supplementation with $n-3$ PUFA has been reported to diminish, not change and enhance, the production of various cytokines, including IL-1, IL-2, IL-6 and TNF- $\alpha$ (Endres, 1996; Meydani, 1996; Blok et al. 1997; Calder, 1997; Grimble \& Tappia, 1998; Wallace et al. 2001). Our laboratory was first to demonstrate that $n-3$ PUFA consumption was associated with a significant impairment of in vivo IL-12 production in mice (Fritsche et al. 1999, 2000).

IL-12 is produced by activated myelomonocytic cells (D'Andrea et al. 1992; Hsieh et al. 1993). The biologically active form of IL-12 is a heterodimeric molecule (p70) composed of a $40 \mathrm{kDa}(\mathrm{p} 40)$ and a $35 \mathrm{kDa}(\mathrm{p} 35)$ subunit (Podlaski et al. 1992). IL-12 is a critical factor for the development of $\mathrm{T}$ helper 1 cells and initiation of cellmediated immune responses against a variety of pathogens (Hsieh et al. 1993; Trinchieri, 1995). The unique ability of IL-12 to direct $\mathrm{T}$ helper 1 cell development and cellular immunity explains its key role in the development of certain inflammatory and autoimmune diseases (Adorini et al. 1997). Therefore, we believe it is essential to define the mechanisms by which $n$-3 fatty acids affect IL-12 production in order to maximize the potential therapeutic anti-inflammatory effects without compromising important anti-microbial or anti-tumour functions of the immune system.

Recent studies suggest that fatty acids share many properties with classic steroid hormones in that they can bind nuclear receptors and regulate target gene expression. A variety of fatty acids were shown to be ligands for a novel family of nuclear receptors called PPAR (Krey et al. 1997). Three isoforms of PPAR have been identified: PPAR $\alpha$, PPAR $\delta$ and PPAR $\gamma$ (Kliewer et al. 1994). PPAR $\gamma$ has been shown to be an important modulator of inflammation (Gelman et al. 1999). It mainly serves as a down-regulator of the activity of many immune cells (Jiang et al. 1998; Ricote et al. 1998). Many different fatty acids can bind and activate PPAR $\gamma$, including PUFA from both the $n-6$ and $n-3$ families (Krey et al. 1997; Xu et al. 1999). To date, the exact contribution of the PPAR $y$ pathway to the immunoregulatory properties of fatty acids has not been defined. Our hypothesis was that $n-3$ PUFA inhibit IL-12 production through activating PPAR $\gamma$. In the present study we used thioglycolate-elicited mouse macrophages as an in vitro cell model system to study the effects of fatty acids and PPAR $\gamma$ ligands on IL-12 biosynthesis. 


\section{Materials and methods}

\section{Reagents}

Mouse recombinant interferon (IFN) $\gamma$ was purchased from R\&D (Minneapolis, MN, USA). Lipopolysaccharide (LPS) from Escherichia coli was purchased from Sigma Chemical Co. (St Louis, MO, USA). 15-Deoxy-prostaglandin (PG) $\mathrm{J}_{2}$, all fatty acids and fatty acids metabolites were purchased from Caymen Chemical (Ann Arbor, MI, USA). Rosiglitazone was extracted with ethanol from rosiglitazone maleate tablets purchased from SmithKline Beecham Pharmaceuticals (Philadelphia, PA, USA). GW9662, a PPAR $\gamma$ antagonist, was a gift from GlaxoSmithKline (Research Triangle Park, NC, USA). WY14643, a selective PPAR $\alpha$ activator, was purchased from Biomol (Plymouth Meeting, PA, USA).

\section{Animals}

Female specific-pathogen-free BALB/cAnNHsd mice (610 weeks old) were used in all experiments (Harlan, Indianapolis, IN, USA). Upon arrival mice were placed in polycarbonate micro-isolator cages (three to four animals per cage) in an environmentally controlled room $\left(21-24^{\circ} \mathrm{C}\right.$, $50-60 \%$ relative humidity). A $12 \mathrm{~h}$ light-dark cycle was maintained throughout the study. Animals had free access to distilled water and food (Mouse Chow 5008; Ralston Purina Co., Richmond, IN, USA). Animal housing, handling and sample collection procedures conformed to policies and recommendations of the University of Missouri's Laboratory Animal Care and Use Committee.

\section{Cell collection and stimulation}

Mouse peritoneal macrophages were used for all experiments. To collect these cells, mice were injected intraperitoneally with $2 \mathrm{ml}$ sterile Brewer's thioglycolate broth (Sigma Chemical Co.). After $4 \mathrm{~d}$, peritoneal exudate cells were collected by flushing the peritoneal cavity twice with $8 \mathrm{ml}$ sterile ice-cold PBS. Cells were pelleted in a centrifuge $(500 \mathrm{~g}, 10 \mathrm{~min})$ and then resuspended in Roswell Park Memorial Institute 1640 medium (GibcoBRL, Grand Island, NY, USA) containing fetal bovine serum (20 g/l), $25 \mathrm{mM}$-HEPES and $2 \mathrm{~mm}$-glutamine. The concentration of cells was determined electronically (Coulter Electronics Inc., Miami, FL, USA) and then adjusted to a final concentration of $2 \times 10^{6} \% \mathrm{ml}$. Aliquots of each cell preparation were deposited on a glass slide and stained (Wright's stain) for cell differentials. Our cell populations were routinely $85-95 \%$ macrophages, based on cell morphology and staining properties. The remaining cells in our cell preparations were predominately lymphocytes, with a small number of neutrophils, eosinophils, basophils and mast cells. We made no effort to further enrich our cell preparations for macrophages.

Unstained cells were cultured in twenty-four-well or forty-eight-well tissue culture plates (Corning; Corning, NY, USA). To stimulate IL-12 production, IFN $\gamma$ (10 U/ $\mathrm{ml}$ ) was added to the wells, followed by the addition of LPS $(0 \cdot 1 \mu \mathrm{g} / \mathrm{ml})$ or Listeria monocytogenes $\left(10^{6}\right.$ colony forming units $/ \mathrm{ml})$. One hour after addition of Listeria, gentamycin $(50 \mu \mathrm{g} / \mathrm{ml})$ was added to Listeria-treated wells to kill extracellular bacteria. Control wells received the same amount of antibiotic at this time. After $24 \mathrm{~h}$ of incubation, the plates were centrifuged $(500 \mathrm{~g}$ for $10 \mathrm{~min})$ and then supernatant fractions were collected and stored at $-70^{\circ} \mathrm{C}$ for future cytokine analysis.

Treatment of cells with PPAR $\gamma$ ligands, fatty acids, fatty acid metabolites and PPAR $\gamma$ antagonist

In a pilot study we demonstrated that PPAR $\gamma$ ligands were equally effective if added $4 \mathrm{~h}$ before or simultaneously with the addition of stimuli, but did not show any effect if added $4 \mathrm{~h}$ after the stimulation of cells (results not shown). Therefore, in all subsequent experiments PPAR $\gamma$ ligands were added to cells shortly before $(5-15 \mathrm{~min})$ the addition of stimuli. PPAR $\gamma$ ligands were delivered to cells dissolved in ethanol. To simulate the cell treatment with the PPAR $\gamma$ agonists, fatty acids and the various fatty acid metabolites tested were also delivered in ethanol. The PPAR $\gamma$ antagonist GW9662 was dissolved in dimethylsulfoxide according to the manufacturer's instructions. Cells were incubated for $2 \mathrm{~h}$ with GW9662 before stimulating IL-12 biosynthesis. Control cells were cultured with dimethylsulfoxide only. The final concentration of ethanol and dimethylsulfoxide never exceeded 4 and $2 \mathrm{~g} / \mathrm{l}$ respectively. These concentrations were not toxic to the cells, as determined by cell viability at the end of the incubation period (described later).

Following treatment with PPAR $\gamma$ ligands and immune stimulation as described earlier, cells were incubated for an additional $22 \mathrm{~h}$ at $37^{\circ} \mathrm{C}$ in a $5 \% \mathrm{CO}_{2}$ atmosphere. Plates were gently spun $(200 \mathrm{~g}, 5 \mathrm{~min})$ to pellet the cells, then the supernatant fractions were collected for IL-12 determination via ELISA.

\section{Cell viability assay}

In all experiments the viability of cells following treatment was determined using Cell Titer 96 Aqueous One Solution (Promega, Madison, WI, USA) according to the manufacturer's instructions. Briefly, to $50 \mu \mathrm{l}$ supernatant fraction and cells that were left behind in each well, $50 \mu \mathrm{l}$ fresh media and $20 \mu \mathrm{l}$ MTS tetrazolium dye (3(4,5-dimethylthiazol-2-yl)-5-(3-carboxymethoxyphenyl)-2(4-sulfophenyl)-2H-tetrazolium, inner salt) were added. Plates were incubated at $37^{\circ} \mathrm{C}$ for $30 \mathrm{~min}$, and then $100 \mu \mathrm{l}$ liquid from each well was transferred to a ninetysix-well ELISA plate to determine the absorbance at $492 \mathrm{~nm}$ using a plate reader.

\section{IL-12 and TNF- $\alpha$ determinations}

Commercially available ELISA kits (R\&D) were used for measuring the concentration of IL-12p70 and TNF- $\alpha$ concentrations in the cell culture supernatant fraction samples. Briefly, ninety-six-well ELISA plates (Nunc, Naperville, IL, USA) were coated with capture antibody (e.g. rat antimouse IL-12p70 antibody) overnight. The next day, plates were treated with blocking buffer (i.e. bovine serum albumin $(10 \mathrm{~g} / \mathrm{l}), 50 \mathrm{~g}$ sucrose/l PBS with $0 \cdot 5 \mathrm{~g}$ sodium azide/l) 
to block non-specific binding. Various dilutions of samples and standards were incubated in the plates for $2 \mathrm{~h}$ before biotinylated goat anti-mouse cytokines antibody was added. After $2 \mathrm{~h}$, plates were washed three times with wash buffer (PBS with $0 \cdot 5 \mathrm{~g}$ Tween 20/1) followed by the addition of streptavidin-horseradish (Armoracia Rusticana) peroxide solution. Following a $20 \mathrm{~min}$ equilibration period, one-step substrate (DAKO Corp., Carpinteria, CA, USA) was added. After 20 min colour development the reaction was stopped with $2 \mathrm{M}-\mathrm{H}_{2} \mathrm{SO}_{4}$ acid. All the treatments were conducted at room temperature. The absorbance was measured on an ELISA plate reader at $450 \mathrm{~nm}$ with a reference reading at $620 \mathrm{~nm}$. The detection limit for the IL-12p70 and TNF- $\alpha$ ELISA kits were 23 and $16 \mathrm{pg} / \mathrm{ml}$ respectively. All samples were assayed in duplicate.

\section{Statistical analyses}

Results are expressed as mean values with their standard errors. Cytokine production data were analysed by oneway ANOVA. For most experiments, cell preparations from separate mice were treated as independent experimental units. Data represent values from replicate wells from the same pooled cell population. In all cases, when a significant difference $(P<0 \cdot 05)$ occurred among different treatment groups, treatment mean differences were identified by Fisher's protected least significant difference test. All analyses were conducted on a Macintosh computer with StatView II software (version 1.3.2; Abacus Concepts, Berkeley, CA, USA).

\section{Results \\ PPAR $\gamma$ ligands inhibit IL-12 and TNF- $\alpha$ production by mouse peritoneal macrophages}

Two PPAR $\gamma$ ligands, 15-deoxy-PGJ ${ }_{2}$ and rosiglitazone, were tested for their effect on IL-12 production by thioglycolate-elicited murine macrophages following either infection with L. monocytogenes or LPS stimulation. PPAR $\gamma$ agonists dose-dependently inhibited IL-12 production, but had little or no effect on TNF- $\alpha$ production. For example, L. monocytogenes-induced IL-12 production was reduced by approximately $50 \%$ by $0.1 \mu \mathrm{M}$-rosiglitazone, with little additional inhibition noted at $1 \cdot 0 \mu \mathrm{M}$. $10 \cdot 0 \mu \mathrm{M}$-rosiglitazone decreased IL-12p70 biosynthesis further (approximately $30 \%$ of untreated cells) and tumour necrosis $\alpha$ production was significantly diminished (approximately $50 \%$ of controls). We observed similar rosiglitazonemediated reductions in IL-12 production from mouse macrophages stimulated with LPS rather than with $L$. monocytogenes (results not shown). We determined cell viability at the end of each experiment and found that the inhibitory effects of PPAR $\gamma$ agonist treatment on macrophage IL-12 production were not due to cell toxicity. Rosiglitazone was not toxic to these cells at all of the concentrations used; however, $10 \mu \mathrm{M}-15$-deoxy-PGJ 2 did induce a considerable degree of cell death (results not shown). We also tested the impact of WY14643, a selective PPAR $\alpha$ activator, on IL-12 biosynthesis and found that it was without effect at concentrations $<10 \mu \mathrm{M}$. At a concentration of $10 \mu \mathrm{M}$, WY14643 modestly reduced mouse macrophage IL-12p70 production by 10 to $15 \%$ of untreated cells.

\section{Fatty acids and their oxidation products reduce $I L-12$ production}

The addition of non-esterified PUFA in their native form (i.e. unoxidized) to mouse peritoneal macrophages decreases IL-12p70 production (Fig. 1(A)). The reduction was dose-dependent and varied depending on the fatty acid used. Of the fatty acids tested, arachidonic acid (AA, 20:4n-6) and docosahexaenoic acid (DHA, $22: 6 n-3)$ were the most potent at reducing IL-12 production. The impact of linoleic acid (LA, 18:2n-6) was more variable than that of AA or DHA, and EPA (20: $5 n-3)$ had the least effect on IL-12p70 production. Exposure of cells to NEFA concentrations $\geq 50 \mu \mathrm{M}$ reduced cell viability (results not shown). Therefore, all subsequent experiments were conducted at a concentration of $25 \mu \mathrm{M}$.

Next, we tested oxidized metabolites of LA, AA, EPA (i.e. 9-hydroxyoctadecadienoic acid, 9-hydroxyeicosatetraenoic acid and 9-hydroxyeicosapentaenoic acid respectively). These fatty acid metabolites dose-dependently reduced IL-12p70 production (Fig. 1(B)). The rank order of their potency was 9-hydroxyeicosatetraenoic acid $>9$-hydroxyoctadecadienoic acid >9-hydroxyeicosapentaenoic acid, which is consistent with the relative potency of the native fatty acids these metabolites were derived from (i.e. AA, LA and EPA). Furthermore, it was clear that the oxidized metabolites were more potent than the native fatty acid, the former having an $\mathrm{IC}_{50}$ (median inhibitory concentration) between 1 and $4 \mu \mathrm{M}$.

GW9662, a PPAR $\gamma$ antagonist, partially reversed rosiglitazone's effect on IL-12 production, but not that of fatty acids

GW9662 is a putative PPAR $\gamma$ antagonist. In order to determine whether this drug functioned as a PPAR $\gamma$ antagonist in our cell culture system, we pretreated our mouse macrophage preparations with varying concentrations of GW9662. After $2 \mathrm{~h}$ we added rosiglitazone $(20 \mu \mathrm{M})$ to the cells and then stimulated IL-12 production with IFNy and LPS as described previously. As expected, rosiglitazone inhibited IL-12 production. The pretreatment of cells with GW9662 at $10 \mu \mathrm{M}$ almost completely abrogated inhibitory effects of rosiglitazone on mouse macrophage IL-12 production (results not shown). If PUFA-mediated inhibition of IL-12 production is mediated by PPAR $\gamma$, then treatment with this PPAR $\gamma$ antagonist should abrogate the effect of PUFA. Therefore, mouse peritoneal macrophages were pretreated with GW9662 for $2 \mathrm{~h}$ before the addition of various PUFA at $25 \mu \mathrm{M}$. PUFA treatment reduced IL-12 production, yet GW9662 pretreatment did not prevent the inhibitory actions of these PUFA on IL-12 production (Fig. 2). 


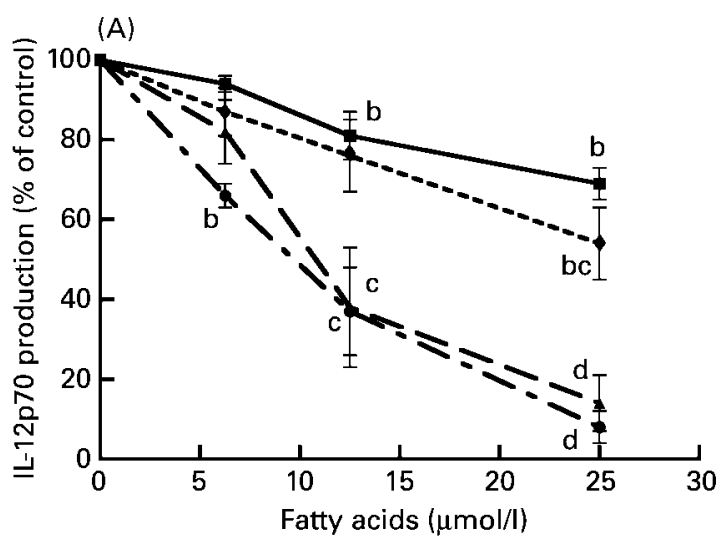

(B)

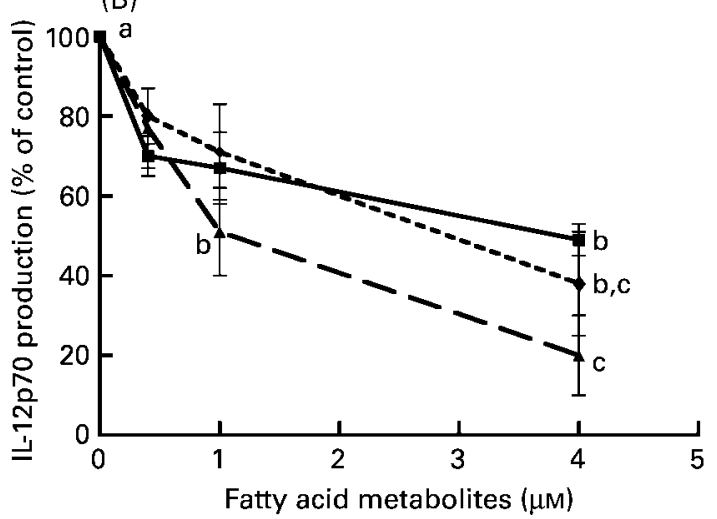

Fig. 1. PUFA and their oxidized metabolites diminish IL-12p70 production by murine macrophages. Thioglycolate-elicited macrophages were isolated from the peritoneums of female specificpathogen-free BALB/c mice and cultured as described on p. 734 . Briefly, cells were resuspended in Roswell Park Memorial Institute 1640 medium with fetal bovine serum $(20 \mathrm{~g} / \mathrm{l})$ at a final concentration of $2 \times 10^{6} / \mathrm{ml}$ and cultured in forty-eight- or twenty-four-well tissue culture plates. Fatty acids (Fig. $1(\mathrm{~A}) ;-\mathbf{-}-$, linoleic acid; $-\mathbf{\Delta}-$, arachidonic acid; - - - - - - , docosahexaenoic acid; -----, EPA) or various oxidized metabolites (Fig. 1(B); - - -, 9-hydroxyoctadeca-

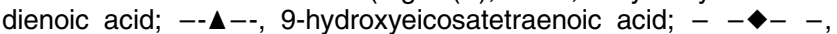
9-hydroxyeicosapentaenoic acid) dissolved in ethanol were added to cell suspensions at the indicated concentrations. After $5-10 \mathrm{~min}$, IL-12p70 biosynthesis was stimulated by adding interferon $\gamma(10 \mathrm{U} / \mathrm{ml})$ and lipopolysaccharide $(0.1 \mu \mathrm{g} / \mathrm{ml})$. Cells were cultured at $37^{\circ} \mathrm{C}$ in a $5 \% \mathrm{CO}_{2}$ environment for $24 \mathrm{~h}$. Supernatant fractions were collected, then analysed for IL-12p70 by ELISA. Values are means from three wells with their standard errors shown by vertical bars (representative of three independent experiments). The actual concentrations of IL-12p70 in the untreated cultures were 1056 (SED 152) and 803 (SED 71) pg/ml for Fig. 1(A) and Fig. 1(B) respectively. a,b,c,d Mean values with unlike superscript letters were significantly different $(P<0.05)$.

\section{Discussion}

In the present study we established an in vitro cell culture model to establish whether long-chain $n$-3 PUFA were reducing IL-12 production via a PPAR $\gamma$ dependent process. We used thioglycolate-elicited mouse peritoneal macrophages, which are known to express high levels of PPAR $y$ (Huang et al. 1999). Next we confirmed what others have previously reported (Chung et al. 2000; Alleva et al. 2002), that in vitro treatment of these cells with two compounds that bind and activate PPAR $\gamma$ (i.e. 15-deoxy-PGJ ${ }_{2}$ and rosiglitazone) reduce the secretion of this pro-inflammatory cytokine in a dose-dependent manner. Several research teams, however,

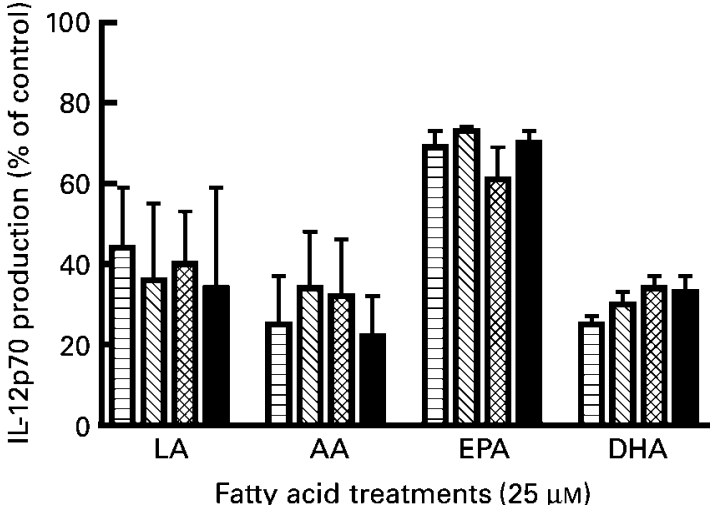

Fig. 2. Pretreatment with a PPAR $y$ antagonist does not reverse the inhibitory effect of PUFA on lipopolysaccharide-induced IL-12p70 production by mouse macrophages. 目, $0.0 \mu \mathrm{M}-\mathrm{GW} 9662 ; \mathbb{\mathbb { }}, 0.1 \mu \mathrm{M}-$ GW9662; $\otimes, 1.0 \mu \mathrm{M}-\mathrm{GW} 9662 ; \mathbf{\square}, 10.0 \mu \mathrm{M}-\mathrm{GW} 9662$. LA, linoleic acid; AA, arachidonic acid; DHA, docosahexaenoic acid. Thioglycolate-elicited mouse peritoneal macrophages were collected and cultured as described on p. 734. GW9662, a PPAR $\gamma$ antagonist, was added to cells at a final concentration of $10 \mu \mathrm{M}$. After $2 \mathrm{~h}, \mathrm{LA}, \mathrm{AA}$, EPA or DHA was added to the cells at a final concentration of $25 \mu \mathrm{M}$, immediately followed by interferon $\gamma$ and lipopolysaccharide stimulation. Cells were cultured at $37^{\circ} \mathrm{C}$ for $24 \mathrm{~h}$. Cell-free supernatant fractions were assayed for IL-12p70 by ELISA. Values are means with their standard errors shown by vertical bars (three independent experiments). While PUFA treatment significantly reduced IL-12p70 production $(P<0.005)$, GW9662 did not have a significant effect on IL-12p70 production under any of the conditions studied here $(P>0.05)$. The actual concentrations of $I L-12 p 70$ in the cultures treated with vehicle alone were 1137 (SEM 121) $\mathrm{pg} / \mathrm{ml}$ for the LA, AA and EPA-treated cells and 1655 (SEM 182) $\mathrm{pg} / \mathrm{ml}$ for the DHA-treated cells.

have demonstrated that some of the actions of 15-deoxy$\mathrm{PGJ}_{2}$ can occur independently of PPAR $\gamma$ (Petrova et al. 1999; Thieringer et al. 2000; Hinz et al. 2003). In contrast to 15 -deoxy-PGJ ${ }_{2}$, rosiglitazone at low concentrations $(\leq 1 \mu \mathrm{M})$ is believed to function exclusively through activation of PPAR $\gamma$ (Willson et al. 2000). The concentration of rosiglitazone at which we observed $50 \%$ inhibition of IL-12 production (i.e. $0 \cdot 1 \mu \mathrm{M}$ ) is similar to the $\mathrm{EC}_{50}$ (half effective concentration) reported in a PPAR-GAL4 transactivation assay (Willson et al. 2000).

Researchers have shown that a number of fatty acids can bind and activate PPAR $\gamma$ at $\mu \mathrm{M}$ concentrations (Xu et al. 1999). Oxidized PUFA in particular (i.e. 9-hydroxyoctadecadienoic acid) are putative PPARy agonists (Nagy et al. 1998). Thus, after demonstrating that our in vitro cell system was sensitive to PPAR $\gamma$-dependent regulation of IL-12 biosynthesis, we tested the impact of various native and oxidized PUFA. We found that similar to known PPAR $\gamma$ agonists, treatment of murine macrophages with native and oxidized PUFA reduced IL-12 production in a dose-dependent manner. The relative potency we observed was rosiglitazone $>$ oxidized PUFA $>$ native PUFA. Among the PUFA tested the relative potency was $\mathrm{DHA}=\mathrm{AA}>\mathrm{EPA}=\mathrm{LA}$.

Previously our laboratory has reported that $n-3$ PUFA found in fish oils, EPA or DHA were equally effective at reducing in vivo IL-12 production in mice (Fritsche et al. 1999, 2000). Thus, we were surprised when DHA distinguished itself from EPA in its potency for reducing 
IL-12 production in vitro. It is possible that DHA might have unique actions over those of EPA. For example, DHA, but not EPA, was recently proposed to be a natural ligand of retinoid $X$ receptor (de Urquiza et al. 2000). This receptor heterodimerizes with PPAR $\gamma$, as well as with other nuclear transcription factors (Willson et al. 2000; Chawla et al. 2001). The physiological consequences of DHA's interaction with retinoid $\mathrm{X}$ receptor are poorly understood at this time. It is unclear if interaction with retinoid $\mathrm{X}$ receptor is what distinguishes DHA's greater potency on IL-12 biosynthesis over that of the closely related $n-3$ fatty acid, EPA.

The relatively high potency of the $n-6$ fatty acid, AA, over its precursor $n-6$ fatty acid (i.e. LA) is more easily understood. We have determined that the inhibitory activity of exogenous AA requires endogenous cyclooxygenase (COX)-2 activity. In contrast, the use of COX-2 inhibitors did not significantly alter the inhibition of IL-12 biosynthesis by LA, EPA or DHA (results not shown).

Our original hypothesis was that $n$-3 PUFA down-regulated IL-12 production through a PPAR $\gamma$-dependent process. However, our in vitro results with a PPAR $\gamma$ antagonist, GW9662, suggest that fatty acid-mediated inhibition of IL12 production is independent of PPAR $\gamma$. We found that pretreatment of cells with GW9662 was able to abrogate the inhibitory action of rosiglitazone, a PPAR $\gamma$-specific agonist, on in vitro IL-12 biosynthesis. However, GW9662 pretreatment did not alter the inhibitory effect of PUFA treatment on mouse macrophage IL-12 production. At the time of these studies, biphenol A diglycidyl ether was the only other PPAR $y$ antagonist known (Wright et al. 2000). We found biphenol A diglycidyl ether to be toxic to primary mouse peritoneal macrophages and were unable to successfully carry out any experiments with it (results not shown).

The concentrations of PUFA that we used in the present study were relatively low $(\leq 25 \mu \mathrm{M})$ compared with those commonly used in transactivation assays that originally defined PUFA as PPAR agonists (Kliewer et al. 1997). Clearly, the potency of fatty acids to activate PPAR $\gamma$ is much lower than that of synthetic activators such as rosiglitazone (Krey et al. 1997). At this time the question as to whether fatty acids serve as endogenous PPAR $\gamma$ ligands remains controversial. However, it seems feasible that under certain physiological conditions, such as fasting, infection and inflammation, systemic or local concentration of NEFA may reach levels that are conducive to their acting via PPAR $\gamma$. Furthermore, it seems entirely possible that under most circumstances it is not the native fatty acid, but rather a metabolite that acts as a PPAR $\gamma$ ligand. For example, in our present experiments the effect of exogenous AA treatment on IL-12 production may have been mediated in part through the production of one or more metabolites such as $\mathrm{PGE}_{2}$ or 15 -deoxy-PGJ $\mathrm{P}_{2}$. Others have demonstrated that $\mathrm{PGE}_{2}$ is a potent inhibitor of human IL-12 production (van der Pouw Kraan et al. 1995). In our present study we did not directly test the impact of $\mathrm{PGE}_{2}$, but rather did show that 15-deoxy-PGJ ${ }_{2}$, another metabolite of AA produced by macrophages (Fitzpatrick \& Wynalda, 1983; Shibata et al. 2002), was quite potent at inhibiting IL-12 production. This eicosanoid may serve as part of an anti-inflammatory negative feedback loop in macrophages. Furthermore, we found that fatty acid oxidation products were much more potent than their native fatty acids in inhibiting IL-12 production.

The major finding presented here is that PUFA-mediated reduction of in vitro IL-12 biosynthesis by mouse macrophages appears to be independent of PPAR $\gamma$. Further, we found little evidence to support a role for PPAR $\alpha$ in regulating IL-12 production in macrophages. However, we believe that fatty acids may reduce IL-12 production via interactions with PPAR $\delta$ (otherwise known as PPAR $\beta$ ). Of the three members of the PPAR family, PPAR $\delta$ is the least well understood. Recently Lee et al. (2003a) demonstrated that activation of PPAR $\delta$ with a synthetic agonist (GW501516) reduces the expression of several pro-inflammatory genes in murine macrophages (i.e. monocyte chemoattractant protein-1, IL-1 $\beta$, but not TNF- $\alpha$ or matrix metalloproteinase-9). Unfortunately, these researchers did not measure IL-12 production. Welch et al. (2003) recently demonstrated that rosiglitazone at concentrations of $50 \mu \mathrm{M}$ inhibit inducible nitric-oxide synthase and IL-12p40 gene expression in murine macrophages in a PPAR $\gamma$-independent manner. The authors suggest that PPAR $\gamma$ and PPAR $\delta$ (otherwise known as PPAR $\beta$ ) have overlapping transactivation and transrepression functions in macrophages. Thus, it seems possible that fatty acid modulation of IL-12 biosynthesis may occur through PPAR $\delta$ and not PPAR $\gamma$. Unfortunately, at the time that our present studies were conducted, agonists and antagonists specific for PPAR $\delta$ were not available.

In addition to interaction with PPAR $\delta$ there are several alternative mechanisms through which $n$-3 PUFA might reduce IL-12 biosynthesis. First, we believe that $n-3$ PUFA-mediated reduction in IFN $\gamma$ receptor expression may play an important role. We have previously reported that feeding mice a diet high in $n$-3 PUFA was associated with a $25-50 \%$ reduction in IFN $\gamma$ receptor expression on immune cells (Feng et al. 1999). IFN $\gamma$ signalling via phosphorylation of signal transducers and activators of transcription (STAT1) is essential for early in vivo IL-12 biosynthesis following an infection (Flesch et al. 1995). We have recently found that macrophages obtained from mice fed a diet with fish oil (i.e. rich in $n$-3 PUFA) have significantly lower levels of phosphorylated STAT1 following treatment with IFN $\gamma$ compared with macrophages isolated from mice fed a control diet free of $n-3$ PUFA (results not shown). STAT1 plays a central role in the induction of many IFN $\gamma$-dependent pro-inflammatory genes, including IL-12 (Ramana et al. 2002). Second, recent findings suggest that reactive oxygen species can have an inhibitory effect of STAT1 signalling (Chen, 2003). n-3 PUFA and AA treatment may enhance the production of free radicals within activated macrophages and thus oxidative stress might play a role in $n$-3 PUFAmediated inhibition of IL-12 production. Third, Lee et al. $(2003 b)$ have suggested that PUFA interfere with toll-like receptor signalling pathways in macrophages. Toll-like receptors recognize specific components conserved among micro-organisms and help macrophages and other cells of the innate immune system respond to infection (Takeda et al. 2003). Lee et al. (2003b) showed that in vitro treatment of cells with PUFA such as DHA, 
EPA, AA and LA diminish, while saturated fatty acids enhance toll-like receptor signalling. Usually, signalling via both toll-like and IFN $\gamma$ receptors is required for optimal macrophage activation and subsequent IL-12 biosynthesis (Ehrt et al. 2001), thus interference with either pathway would be expected to have a negative effect on IL-12 production.

In conclusion, we have confirmed that PPAR $\gamma$ agonists significantly diminish IL-12p70 production by mouse peritoneal macrophages and that this inhibition can be abrogated by pretreatment of cells with GW9662, a PPAR $\gamma$ antagonist. Furthermore, we have demonstrated that fatty acids and their oxidation products can also inhibit IL-12 production in a dose-dependent manner. However, GW9662 does not prevent the inhibitory action of fatty acids on IL-12 production by macrophages. Our present results suggest that fatty acid-mediated inhibition on IL12 production is independent of PPAR $\gamma$. Elucidation of the possible involvement of PPAR $\delta$ or other molecular mechanism(s) through which fatty acids mediate inhibition of IL-12 production awaits further study.

\section{References}

Adorini L, Aloisi F, Galbiati F, et al. (1997) Targeting IL-12, the key cytokine driving th1-mediated autoimmune diseases. Chem Immunol 68, 175-197.

Alleva DG, Johnson EB, Lio FM, et al. (2002) Regulation of murine macrophage proinflammatory and anti-inflammatory cytokines by ligands for peroxisome proliferator-activated receptor-gamma: Counter-regulatory activity by IFN-gamma. J Leukoc Biol 71, 677-685.

Blok WL, Deslypere JP, Demacker PN, et al. (1997) Pro- and anti-inflammatory cytokines in healthy volunteers fed various doses of fish oil for 1 year. Eur J Clin Invest 27, 1003-1008.

Calder PC (1996) Effects of fatty acids and dietary lipids on cells of the immune system. Proc Nutr Soc 55, 127-150.

Calder PC (1997) n-3 Polyunsaturated fatty acids and cytokine production in health and disease. Ann Nutr Metab 41, 203-234.

Calder PC (1998) Dietary fatty acids and lymphocyte functions. Proc Nutr Soc 57, 487-502.

Chawla A, Repa JJ, Evans RM \& Mangelsdorf DJ (2001) Nuclear receptors and lipid physiology: Opening the X-files. Science 294, 1866-1870

Chen C-W, Chang Y-H, Tsi C-J \& Lin W-W (2003) Inhibition of IFN- $\gamma$-mediated inducible nitric oxide synthase induction by the peroxisome proliferator-activated receptor $\gamma$ agonist, 15deoxy- $\Delta^{12,14}$-prostaglandin $\mathrm{J}_{2}$, involves inhibition of upstream janus kinase/STAT1 signaling pathway. J Immunol 171, 979-988.

Chung SW, Kang BY, Kim SH, et al. (2000) Oxidized low density lipoprotein inhibits interleukin-12 production in lipopolysaccharide-activated mouse macrophages via direct interactions between peroxisome proliferator-activated receptor-gamma and nuclear factor-kappa b. J Biol Chem 275, 32681-32687.

D'Andrea A, Rengaraju M, Valiante NM, et al. (1992) Production of natural killer cell stimulatory factor (NKSF/IL-12) by peripheral blood mononuclear cells. J Exp Med 176, 1387-1398.

de Urquiza AM, Liu S, Sjoberg M, et al. (2000) Docosahexaenoic acid, a ligand for the retinoid $\mathrm{X}$ receptor in mouse brain. Science 290, 2140-2144.

Ehrt S, Schnappinger D, Bekiranov S, et al. (2001) Reprogramming of the macrophage transcriptome in response to interferon-gamma and mycobacterium tuberculosis: Signaling roles of nitric oxide synthase- 2 and phagocyte oxidase. $J$ Exp Med 194, 1123-1140.

Endres S (1996) $n$-3 Polyunsaturated fatty acids and human cytokine synthesis. Lipids 31, Suppl, S239-S242.

Feng C, Keisler DH \& Fritsche KL (1999) Dietary omega-3 polyunsaturated fatty acids reduce IFN-gamma receptor expression in mice. J Interferon Cytokine Res 19, 41-48.

Fitzpatrick FA \& Wynalda MA (1983) Albumin-catalyzed metabolism of prostaglandin D2. Identification of products formed in vitro. J Biol Chem 258, 11713-11718.

Flesch I, Hess JH, Huang S, et al. (1995) Early interleukin-12 production by macrophages in response to mycobacterial infection depends on interferon- $\gamma$ and tumor necrosis factor $\alpha . J$ Exp Med 181, 1615-1621.

Fritsche KL, Anderson M \& Feng C (2000) Consumption of eicosapentaenoic acid and docosahexaenoic acid impair murine interleukin-12 and interferon-gamma production in vivo. $J$ Infect Dis 182, Suppl 1, S54-S61.

Fritsche KL, Byrge M \& Feng C (1999) Dietary omega-3 polyunsaturated fatty acids from fish oil reduce interleukin-12 and interferon-gamma production in mice. Immunol Lett $\mathbf{6 5}$, $167-173$.

Gelman L, Fruchart JC \& Auwerx J (1999) An update on the mechanisms of action of the peroxisome proliferator-activated receptors (PPARs) and their roles in inflammation and cancer. Cell Mol Life Sci 55, 932-943.

Grimble RF \& Tappia PS (1998) Modulation of pro-inflammatory cytokine biology by unsaturated fatty acids. Z Ernahrungswiss 37, 57-65.

Harbige LS (1998) Dietary $n-6$ and $n-3$ fatty acids in immunity and autoimmune disease. Proc Nutr Soc 57, 555-562.

Hinz B, Brune K \& Pahl A (2003) 15-deoxy-delta(12,14)-prostaglandin $\mathrm{J} 2$ inhibits the expression of proinflammatory genes in human blood monocytes via a PPAR-gamma-independent mechanism. Biochem Biophys Res Commun 302, 415-420.

Hsieh C, Macatonia SE, Tripp CS, et al. (1993) Development of Th1 $\mathrm{CD} 4^{+} \mathrm{T}$ cells through IL-12 produced by listeria-induced macrophages. Science 260, 547-549.

Huang JT, Welch JS, Ricote M, et al. (1999) Interleukin-4-dependent production of PPAR-gamma ligands in macrophages by 12/15-lipoxygenase. Nature 400, 378-382.

Jiang C, Ting AT \& Seed B (1998) PPAR-gamma agonists inhibit production of monocyte inflammatory cytokines. Nature 391, $82-86$.

Kliewer SA, Forman BM, Blumberg B, et al. (1994) Differential expression and activation of a family of murine peroxisome proliferator-activated receptors. Proc Natl Acad Sci USA 91, $7355-7359$.

Kliewer SA, Sundseth SS, Jones SA, et al. (1997) Fatty acids and eicosanoids regulate gene expression through direct interactions with peroxisome proliferator-activated receptors alpha and gamma. Proc Natl Acad Sci USA 94, 4318-4323.

Krey G, Braissant O, L'Horset F, et al. (1997) Fatty acids, eicosanoids, and hypolipidemic agents identified as ligands of peroxisome proliferator-activated receptors by coactivator-dependent receptor ligand assay. Mol Endocrinol 11, 779-791.

Lee CH, Chawla A, Urbiztondo N, et al. (2003a) Transcriptional repression of atherogenic inflammation: Modulation by PPAR delta. Science 302, 453-457.

Lee JY, Plakidas A, Lee WH, et al. (2003b) Differential modulation of toll-like receptors by fatty acids: Preferential inhibition by $n-3$ polyunsaturated fatty acids. J Lipid Res $\mathbf{4 4}$, 479-486.

Meydani SN (1996) Effect of (n-3) polyunsaturated fatty acids on cytokine production and their biologic function. Nutrition 12, S8-S14. 
Nagy L, Tontonoz P, Alvarez JG, Chen H \& Evans RM (1998) Oxidized LDL regulates macrophage gene expression through ligand activation of PPAR gamma. Cell 93, 229-240.

Petrova TV, Akama KT \& Van Eldik LJ (1999) Cyclopentenone prostaglandins suppress activation of microglia: Down-regulation of inducible nitric-oxide synthase by 15-deoxy-delta 12,14-prostaglandin $\mathrm{J}_{2}$. Proc Natl Acad Sci USA 96, 4668-4673.

Podlaski FJ, Nanduri VB, Hulmes JD, et al. (1992) Molecular characterization of interleukin 12. Arch Biochem Biophys 294, 230-237.

Ramana CV, Gil MP, Schreiber RD \& Stark GR (2002) STAT1dependent and -independent pathways in IFN-gamma-dependent signaling. Trends Immunol 23, 96-101.

Ricote M, Li AC, Willson TM, Kelly CJ \& Glass CK (1998) The peroxisome proliferator-activated receptor-gamma is a negative regulator of macrophage activation. Nature 391, 79-82.

Shibata T, Kondo M, Osawa T, et al. (2002) 15-deoxy-delta 12,14-prostaglandin $\mathrm{J}_{2}$. A prostaglandin $\mathrm{D}_{2}$ metabolite generated during inflammatory processes. J Biol Chem 277, 10459-10466.

Takeda K, Kaisho T \& Akira S (2003) Toll-like receptors. Annu Rev Immunol 21, 335-376.

Thieringer R, Fenyk-Melody JE, Le Grand CB, et al. (2000) Activation of peroxisome proliferator-activated receptor gamma does not inhibit IL-6 or THF-alpha responses of macrophages to lipopolysaccharide in vitro or in vivo. J Immunol 164, $1046-1054$

Trinchieri G (1995) Interleukin-12: A proinflammatory cytokine with immunoregulatory functions that bridge innate resistance and antigen-specific adaptive immunity. Аnпи Rev Immunol 13, 251-276.

van der Pouw Kraan TCTM, Boeije LCM, Smeenk RJT, Wijdenes J \& Aarden LA (1995) Prostaglandin- $E_{2}$ is a potent inhibitor of human interleukin 12 production. $J$ Exp Med 181, 775-779.

Wallace FA, Miles EA, Evans C, et al. (2001) Dietary fatty acids influence the production of Th1- but not Th2-type cytokines. $J$ Leukoc Biol 69, 449-457.

Welch JS, Ricote M, Akiyama TE, Gonzalez FJ \& Glass CK (2003) PPARgamma and PPARdelta negatively regulate specific subsets of lipopolysaccharide and IFN-gamma target genes in macrophages. Proc Natl Acad Sci USA 100, 6712-6717.

Willson TM, Brown PJ, Sternbach DD \& Henke BR (2000) The PPARs: From orphan receptors to drug discovery. J Med Chem 43, 527-550.

Wright HM, Clish CB, Mikami T, et al. (2000) A synthetic antagonist for the peroxisome proliferator-activated receptor gamma inhibits adipocyte differentiation. $J$ Biol Chem 275, $1873-1877$.

Wu D \& Meydani SN (1998) $n-3$ Polyunsaturated fatty acids and immune function. Proc Nutr Soc 57, 503-509.

Xu HE, Lambert MH, Montana VG, et al. (1999) Molecular recognition of fatty acids by peroxisome proliferator-activated receptors. Mol Cell 3, 397-403. 